\title{
Saturated Fractional Design of Experiments: Toughness and Graphite Phase Optimizing in Nihard Cast Irons
}

\author{
J. Asensio-Lozano and J.F. Álvarez-Antolín
}

\author{
(Submitted November 15, 2006; in revised form May 21, 2007)
}

\begin{abstract}
The aim of the present research is to identify the manufacturing factors that exert an active influence on the graphite phase formation in mottled Nihard cast irons constituting the roll shells of duplex work rolls processed by the double pour method during centrifugal casting. The studied rolls, referred to as alloy indefinite chill, were processed at industrial scale and had a core consisting of spheroidal graphite cast iron with a matrix of ferrite and pearlite. An additional aim of this study was to evaluate the effect and extent of these factors on the dynamic toughness response of the roll shell material.

The research methodology employed consisted of the application of a saturated design of experiments with seven factors, eight experiments, and resolution III. The measured responses for graphite were: the volume fraction, count number per unit area, and morphology, determined by quantitative metallography. Impact testing was characterized by Charpy tests on U-notched specimens at $350{ }^{\circ} \mathrm{C}$. The manufacturing factors studied were: the final weight percent of silicon, sulfur, and manganese; the liquidus and the casting temperatures; and, finally, inoculation with SiCaMn and A-type FeSi (with Zr).

The statistical experimental method conducted allowed us to confirm the significance of factors such as the \% $\mathrm{Si}$, the liquidus temperature and inoculation with $\mathrm{SiCaMn}$ on the precipitation of graphite in a white cast iron such as the Nihard irons used in the roll shell, in agreement with the precipitation of graphite in gray cast irons widely reported in the literature. It was also shown that the development of lamellar graphite shapes were favored by an increase in the total equivalent carbon and also by the increase in the amount of A-type FeSi added. Furthermore, the impact toughness was shown to improve with the increase in both the \% $\mathrm{Si}$ and the liquidus temperature.
\end{abstract}

Keywords alloy indefinite chill (AIC), centrifugal casting, design of experiments (DOE), duplex rolls, graphite, toughness

\section{Introduction}

The use of rolls in hot strip mills with the presence of free graphite within the white cast iron microstructure constituting the outer shell dates from the early 1930s. Despite the softening of the periphery of the rolls as a result of the presence of graphite and thus the reduction in wear resistance, this configuration was nevertheless shown to considerably reduce roll breakage and, ultimately, to provide higher durability during the service life of the roll. The presence of graphite in the outer shell greatly improves the ability of the rolls to withstand thermal shocks associated with hot rolling of steel

J. Asensio-Lozano, Departamento de Ciencia de los Materiales e Ingeniería Metalúrgica, Escuela Técnica Superior de Ingenieros de Minas, Universidad de Oviedo, c/ Independencia 13, 33004 Oviedo, Asturias, Spain; and J.F. Álvarez-Antolín, Departamento de Ciencia de los Materiales e Ingeniería Metalúrgica, Escuela Politécnica Superior de Ingeniería, Universidad de Oviedo, Edificio Este, Campus Universitario, 33203 Gijon, Asturias, Spain. Contact e-mail: jasensio@etsimo.uniovi.es. strip (Ref 1,2), reduces friction between the roll and the strip and thus minimizes the applied stress to the strip. The precipitation of free graphite during solidification that is finely dispersed in the chilled microstructure also significantly minimizes the potential for sticking of the strip to the roll (Ref 3).

These types of rolls, known as alloy indefinite chill (AIC) rolls, are composed of an outer ring layer manufactured in mottled Nihard cast iron and a core made of gray cast iron or spheroidal graphite (SG) iron with a ferrite plus pearlite matrix. They are manufactured by the double pour method either statically or, more commonly, by centrifugal casting. Vertical centrifugal cast machines were employed in the present study. The casting of the core melt is preceded by the casting of an interface layer between the shell and the core, with a similar composition to that of the core, to ensure a better joining of the layer to the core, thus giving rise to the so-called double layer type of roll. The essential feature of AIC rolls is the critical balance between alloying elements such as carbon, nickel, and silicon which promote the formation of graphite, and carbide-forming elements such as chromium. The formation of an alloy containing the proper balance of graphite and carbides requires extremely careful selection of melting stock, close control of melting conditions, and rigid control of the composition to obtain the required type and distribution of graphite.

The interest of the present study resides in the attempt to provide the roll manufacturer with the tools to govern the 
formation of the graphite phase in AIC roll layers processed by vertical centrifugal casting by means of the adjustment of the levels of certain metallurgical manufacturing parameters. This control must additionally be fine tuned so as to obtain the optimum toughness in the roll periphery layer.

The research was conducted at industrial scale in a local roll foundry located in Northern Spain. The compositional range used by the roll manufacturer to obtain the desired outer layer is indicated in Table 1 and corresponds to the company's internal specifications. This composition is designed to give a hypoeutectic white cast iron (Ref 4) with the presence of interdendritic graphite embedded within a ledeburitic matrix constituent, in which the austenite becomes partially transformed into martensite on cooling to room temperature. The type, chemistry, and weight of the different additions added as bath inoculants are shown in Table 2. The size of the inoculants ranged between 5 and $20 \mathrm{~mm}$. The temperature for pouring the melt from the furnace into the ladle was around $1380{ }^{\circ} \mathrm{C}$. The usual pouring temperature of the melt forming the layer is around $1320^{\circ} \mathrm{C}$. The roll core, also processed by centrifugal casting, is made in ductile cast iron with a matrix composed of homogeneously distributed ferrite plus pearlite. The most frequent dimensions for these AIC rolls are: diameters in the range of $650-750 \mathrm{~mm}$, and roll barrels of between 1800 and $2200 \mathrm{~mm}$.

This study allowed us to select from among the various controllable manufacturing process variables thought to play a role in the precipitation of graphite those which exert a significant influence over the parameters defining the microstructure characteristics of this phase in the roll ring layers. This is achieved by assigning values to the proposed factors in a saturated DOE that are thought to cause the precipitation of graphite in a flake-like fashion and also provide a higher count number than in actual manufacturing conditions (Ref 5). In addition, the manufacturing factors with a significant influence on the hot impact toughness of the outer shell material of the work rolls studied were also highlighted.

\section{Experimental Design and Technique}

In order to achieve the objectives that give rise to the present research study, a work methodology was designed consisting in the drawing up of a saturated design of experiments (DOE) with seven factors, eight experiments, and resolution III (Ref 6). It is interesting to note that the liquidus temperature monitored during

Table 1 Chemical composition range of the outer ring layers in AIC duplex rolls (in weight percent)

\begin{tabular}{lccccccc}
\hline $\mathbf{C}$ & $\mathbf{M n}$ & $\mathbf{S i}$ & $\mathbf{S}$ & $\mathbf{P}$ & $\mathbf{C r}$ & $\mathbf{N i}$ & $\mathbf{M o}$ \\
\hline $3.2-3.3$ & $0.9-1.0$ & $0.9-1.0$ & $<0.015$ & $<0.035$ & $1.7-1.8$ & $4.2-4.4$ & 0.25 \\
\hline
\end{tabular}

casting is a measured factor, as is the Si. Carbon serves to meet the specified liquidus temperature of a given experiment once the amount of Si on the same experiment is also fixed.

Some of the main concepts to consider in the present DOE are (Ref 7):

Response function: the generic name given to a studied characteristic.

Factors: the selected independent variables that are considered to cause different effects on the responses.

Factor levels or levels: the intensities to which the control factors are changed in a given experiment.

Effect of a factor: the variation of the response function as a result of the variation of such a factor.

Principal effects: the effects on the response function derived from each factor taken separately. In the present DOE, the principal effects include the effects due to the interactions among factors. The principal effects and their interactions can be associated with the terms in a Taylor polynomial development of the response function. For instance, when the third-order interactions of the factors are dismissed, the third-order term in Taylor polynomial is also dismissed. This enables the execution of fractional DOE, reducing the number of experiments, though assuming the possible error incurred in as a result of dismissing the interactions between factors.

Significant effect: the factors significantly different to zero. That is, those effects different to zero due to causes other than system variability or experimental error. As a result, the significant effects are those effects which truly have an influence on the studied responses.

The strategy of a DOE is to formulate the appropriate number of tests that need to be carried out to gain the desired level of knowledge with a minimum number of experiments. Two main types of DOE can be distinguished. On the one hand, there are complete factorial DOE, which require the running of a high number of experiments. However, these are rarely chosen in the initial stage of a research process at industry level for reasons of economy and time limits due to the exponential growth in the number of experiments with the chosen factors to be investigated. On the other hand, fractional factorial DOE allow a high number of factors to be studied with a considerably lower number of experiments to be executed in comparison to the former. The latter is in fact a simplification, in which the loss of information derived from the possible interactions among the chosen factors, known as confusion of the factors, is assumed. It is often employed where the unknown possible interactions have minimal or no influence (Ref 7). Further reduction in the number of experiments can be obtained by opting for higher degrees of fractioning, as occurs with saturated fractional DOE, which are usually chosen during the initial stages of a

Table 2 Chemical composition of inoculants expressed in weight percent with an indication of the regular amounts added to the treatment ladle expressed in $\mathrm{kg} / \mathrm{T}$

\begin{tabular}{lrcccccccccc}
\hline Inoculants & $\mathbf{S i}$ & $\mathbf{C a}$ & $\mathbf{A l}$ & $\mathbf{Z r}$ & $\mathbf{T i}$ & $\mathbf{C}$ & $\mathbf{S}$ & $\mathbf{P}$ & $\mathbf{M n}$ & Fe & Amount added \\
\hline A-type FeSi & 75.0 & 2.5 & 1.4 & 1.6 & $\ldots$ & $\ldots$ & $\ldots$ & $\ldots$ & $\ldots$ & Rest & 1.6 \\
B-type FeSi & 75.4 & 0.5 & 1.0 & $\ldots$ & 0.031 & 0.2 & 0.001 & 0.012 & $\ldots$ & Rest & 0.6 \\
FeMn & 2.0 & $\ldots$ & $\ldots$ & $\ldots$ & $\ldots$ & 5.8 & 0.014 & 0.130 & 69.4 & Rest & 0.8 \\
SiCaMn & 58.3 & 16.4 & 1.1 & $\ldots$ & 0.030 & 0.6 & 0.030 & 0.030 & 14.8 & 7.4 & 0.36 \\
\hline
\end{tabular}


research process based on these statistical control tools. This was the DOE chosen for seven factors, resulting in eight experiments.

Fractional designs are usually denoted by $2_{N}^{k-p}$, where 2 represents the number of levels studied for every factor, $k$ represent the number of factors or metallurgical variables to study, $p$ is the degree of fractioning, and $N$ represents the degree of resolution. The present DOE can be represented by $(2$ III $)$, yielding a total of eight experiments. The degree of resolution in this DOE is III, which indicates the degree of confusion that is present in the estimation of the factors. In this analysis, it is only possible to estimate the principal effects (Ref 7).

Table 3 shows the factors and chosen levels. Table 4 presents the DOE matrix, while Table 5 shows the generators, effects, and confusions.

The experimental procedure that describes the metallographic techniques leading to the measured responses specified above may be summarized as follows. First, samples were cut from the upper part of the roll barrel, corresponding to the position while vertical centrifugal casting took place. The cutting process was conducted on completion of solidification and cooling to room temperature (RT) using a disc-cutting machine. The dimensions of the specimens for metallographic inspection were approximately $15 \times 15 \times 40$ (in $\mathrm{mm}$ ), their major length coinciding with the layer thickness in the direction of the roll radius. Mechanical preparation of the specimens for metallographic inspection was conducted by the classical grinding techniques using 60-120-240 and 600 grit $\mathrm{SiC}$ papers. The specimens were then polished in two consecutive stages, first with $6 \mu \mathrm{m}$ and then with $1 \mu \mathrm{m}$ oil-based diamond paste. For the sake of simplicity in the analysis of the results, the samples were divided into four zones comprised between the periphery and the ring-core roll interface. Five micrographs were randomly chosen for each of the four zones in the aspolished state, totaling 20 micrographs per roll. Micrographs were taken under an Olympus light optical microscope (LOM) PMG3 model connected to an OmniMet ${ }^{\circledR}$ Enterprise device for electronic image data acquisition and archiving. The quantitative metallographic assessment of the graphite phase was performed with an Image ProPlus (version 4.5.0.29) coupled to Materials-Pro module imaging software. In order to conduct the DOE analysis and the derivation of the significant effects, the commercial statistics software package Statgraphics Plus (version 5.1) was employed.

The responses studied in this DOE were $(\operatorname{Ref} 8,9)$ :
1. The volume fraction of graphite, denoted by $V_{\mathrm{v}}$.

2. The number of counts per unit area of graphite, represented by $\# / \mathrm{mm}^{2}$. Each graphite flake is considered an independent count and was therefore counted individually, regardless of the eutectic cell or "rosette" from which it originated.

3. The Feret quotient expressed by: $F_{\max } / F_{\min }$, where $F_{\max }$ is the maximum Feret diameter and $F_{\min }$ stands for the minimum Feret diameter.

4. The percentage of graphite with a lamellar morphology; considering as lamellar those particles whose roundness shape factor, given by the expression: perimeter $^{2} /(4 \pi \times$ area), is higher than 3.5.

5. The toughness value, measured in Charpy U-notched specimens taken from the mid thickness of the roll outer layers. The specimens were cut with their major dimension taken perpendicular to the roll radius and with the notch machined in the roll barrel direction. For this purpose, prisms were cut from the outer layer in the as-cast

Table $4 \quad\left(2_{\text {III }}^{7-4}\right)$ array for DOE

\begin{tabular}{lccccccc}
\hline Experiment number & $\boldsymbol{A}$ & $\boldsymbol{B}$ & $\boldsymbol{C}$ & $\boldsymbol{D}$ & $\boldsymbol{E}$ & $\boldsymbol{F}$ & $\boldsymbol{G}$ \\
\hline 1 & -1 & -1 & -1 & +1 & +1 & +1 & -1 \\
2 & +1 & -1 & -1 & -1 & -1 & +1 & +1 \\
3 & -1 & +1 & -1 & -1 & +1 & -1 & +1 \\
4 & +1 & +1 & -1 & +1 & -1 & -1 & -1 \\
5 & -1 & -1 & +1 & +1 & -1 & -1 & +1 \\
6 & +1 & -1 & +1 & -1 & +1 & -1 & -1 \\
7 & -1 & +1 & +1 & -1 & -1 & +1 & -1 \\
8 & +1 & +1 & +1 & +1 & +1 & +1 & +1 \\
\hline
\end{tabular}

\section{Table 5 Generators and confusions in the (2 $\left.2_{\text {III }}^{7-4}\right)$ array for DOE}

\begin{tabular}{lc}
\hline Generators & Confusions \\
\hline & $A+B D+C E+F G$ \\
$D=A B$ & $B+A D+C F+E G$ \\
$E=A C$ & $C+A E+B F+D G$ \\
$F=B C$ & $D+A B+E F+C G$ \\
$G=A B C$ & $E+A C+D F+B G$ \\
& $F+B C+D E+A G$ \\
& $G+A F+B E+C D$ \\
\hline
\end{tabular}

Table 3 Factors and level description for DOE

\begin{tabular}{|c|c|c|c|}
\hline & \multirow[b]{2}{*}{ Factors } & \multicolumn{2}{|c|}{ Levels } \\
\hline & & Level -1 & Level +1 \\
\hline$A$ & $\% \mathrm{Si}$ & $0.8-0.9$ & $1.1-1.2$ \\
\hline$B$ & $\% \mathrm{~S}$ & 0.01 & $0.04^{\mathrm{a}}$ \\
\hline$C$ & Liquidus temperature & $1210-1215^{\circ} \mathrm{C}$ & $1230-1235^{\circ} \mathrm{C}$ \\
\hline$D$ & Casting temperature & Liquidus temperature $+80{ }^{\circ} \mathrm{C}$ & Liquidus temperature $+120^{\circ} \mathrm{C}$ \\
\hline$E$ & Type A-Ferrosilicon & None & $1.6 \mathrm{~kg} / \mathrm{T}$ \\
\hline$F$ & SiCaMn & $0.3 \mathrm{~kg} / \mathrm{T}$ & $0.5 \mathrm{~kg} / \mathrm{T}$ \\
\hline$G$ & $\% \mathrm{Mn}$ & $0.7-0.8$ & $1.0-1.1$ \\
\hline
\end{tabular}




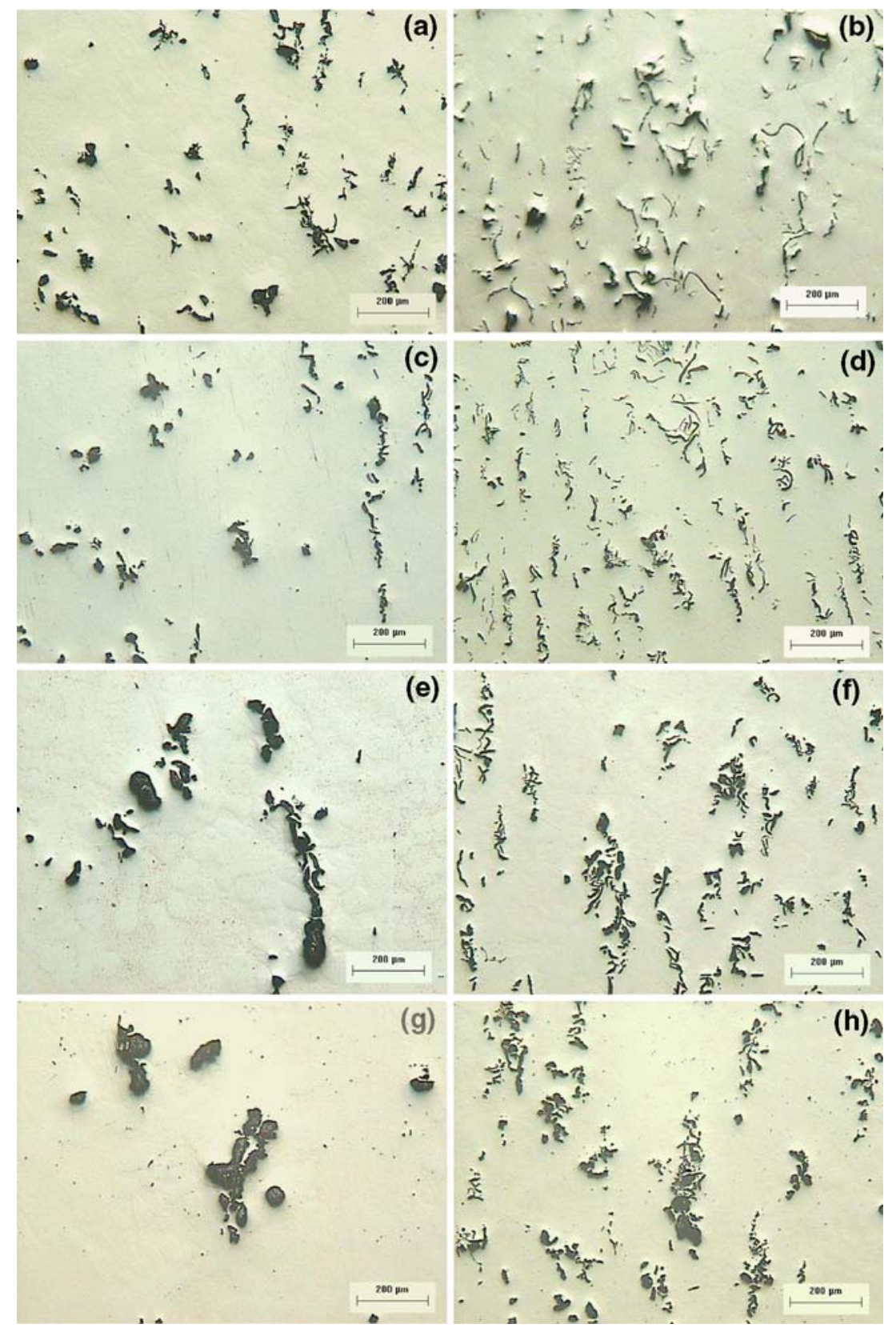

Fig. 1 Selected light optical micrographs in the as-polished state, taken from the mid section of the roll outer layers for each of the eight experiments in the present DOE: (a)-(h)

state. These were then heat treated at $480{ }^{\circ} \mathrm{C}$ for $24 \mathrm{~h}$ at laboratory scale, simulating the industrial heat treatment of these AIC-type rolls. Subsequently, Charpy specimens of the aforementioned geometry were machined out of these prisms, and the tests were conducted at approximately $350{ }^{\circ} \mathrm{C}$.

\section{Results and Discussion}

Figure 1(a)-(h) shows interdendritic graphite flakes in selected light optical micrographs. Graphite formation is the result of partial transformation of the eutectic liquid to give stable eutectic cells that consist of graphite flakes embedded in eutectic austenite. These micrographs correspond to the as-polished state of the mid section in the outer ring layer for each experiment in the DOE.

The results obtained in this research study are presented in Tables 6-12, as well as in Fig. 1-5. Table 6 shows the making process parameters of the eight experiments. Tables 8-11 show the derivation of the effects for each response according to Yates' algorithm (Ref 10). Figures 1-5 illustrate the standardized effects, that is: the numerical value of the effect divided by its standard deviation, which is then represented in normal probability plots; those effects found to be significant are noted with their corresponding letter within each plot.

By representing the data from a normal distribution on a normal probability plot, they will appear aligned. The straight line so defined passes through the point of coordinates $(0,50 \%)$ 
Table 6 Casting parameters measured for each experiment in the DOE

\begin{tabular}{|c|c|c|c|c|c|c|c|c|c|}
\hline \multirow[b]{2}{*}{ Casting parameters } & \multirow[b]{2}{*}{ Units } & \multicolumn{8}{|c|}{ Experiment number } \\
\hline & & 1 & 2 & 3 & 4 & 5 & 6 & 7 & 8 \\
\hline $\mathrm{C}$ & $\%$ & 3.47 & 3.43 & 3.58 & 3.49 & 3.24 & 3.28 & 3.31 & 3.18 \\
\hline $\mathrm{Mn}$ & $\%$ & 0.75 & 1.04 & 1.02 & 0.79 & 1.04 & 0.79 & 0.72 & 1.01 \\
\hline $\mathrm{Si}$ & $\%$ & 0.82 & 1.137 & 0.81 & 1.17 & 0.9 & 1.19 & 0.86 & 1.15 \\
\hline $\mathrm{S}$ & $\%$ & 0.01 & 0.009 & 0.04 & 0.03 & 0.01 & 0.01 & 0.05 & 0.05 \\
\hline $\mathrm{P}$ & $\%$ & 0.03 & 0.03 & 0.03 & 0.03 & 0.03 & 0.03 & 0.03 & 0.03 \\
\hline $\mathrm{Cr}$ & $\%$ & 1.79 & 1.75 & 1.76 & 1.75 & 1.78 & 1.8 & 1.77 & 1.79 \\
\hline $\mathrm{Ni}$ & $\%$ & 4.33 & 4.3 & 4.39 & 4.17 & 4.24 & 4.22 & 4.28 & 4.26 \\
\hline Mo & $\%$ & 0.27 & 0.25 & 0.29 & 0.26 & 0.26 & 0.28 & 0.28 & 0.28 \\
\hline Type A-Ferrosilicon & $\mathrm{kg} / \mathrm{T}$ & 1.6 & 0 & 1.6 & 0 & 0 & 1.6 & 0 & 1.6 \\
\hline Type B-Ferrosilicon & $\mathrm{kg} / \mathrm{T}$ & 0.6 & 3.6 & 0.6 & 3.5 & 3.2 & 0.72 & 2.8 & 0.6 \\
\hline FeMn & $\mathrm{kg} / \mathrm{T}$ & 0.8 & 0.8 & 0.8 & 0.8 & 0.8 & 0.8 & 0.8 & 0.8 \\
\hline SiCaMn & $\mathrm{kg} / \mathrm{T}$ & 0.5 & 0.5 & 0.3 & 0.3 & 0.3 & 0.3 & 0.5 & 0.5 \\
\hline Liquidus temperature & ${ }^{\circ} \mathrm{C}$ & 1214 & 1208 & 1208 & 1204 & 1228 & 1229 & 1228 & 1228 \\
\hline Casting temperature & ${ }^{\circ} \mathrm{C}$ & 1332 & 1288 & 1285 & 1326 & 1349 & 1302 & 1310 & 1342 \\
\hline
\end{tabular}

Table 7 Calculation of the effects by means of Yates' algorithm for the response volume fraction of graphite $\left(V_{\mathrm{v}}\right.$ - percentage)

\begin{tabular}{|c|c|c|c|c|c|c|c|c|c|c|c|c|c|c|}
\hline \multirow[b]{2}{*}{ Experiment } & \multicolumn{7}{|c|}{ Factors } & \multirow[b]{2}{*}{$V_{\mathrm{v}}(\%)$} & \multirow[b]{2}{*}{ I } & \multirow[b]{2}{*}{ II } & \multirow[b]{2}{*}{ III } & \multirow[b]{2}{*}{ Divisor } & \multirow[b]{2}{*}{ Effects } & \\
\hline & $A$ & $\boldsymbol{B}$ & $C$ & $D$ & $E$ & $F$ & $G$ & & & & & & & \\
\hline 1 & -1 & -1 & -1 & +1 & +1 & +1 & -1 & 4.86 & 11.89 & 22.67 & 42.74 & 8 & 5.34 & Mean \\
\hline 2 & +1 & -1 & -1 & -1 & -1 & -1 & +1 & 7.03 & 10.78 & 20.07 & 8.16 & 4 & 2.04 & $A$ \\
\hline 3 & -1 & +1 & -1 & -1 & +1 & -1 & +1 & 4.41 & 9.43 & 4.11 & 0.10 & 4 & 0.02 & $B$ \\
\hline 4 & +1 & +1 & -1 & +1 & -1 & +1 & -1 & 6.36 & 10.64 & 4.05 & 0.14 & 4 & 0.04 & $D$ \\
\hline 5 & -1 & -1 & +1 & +1 & -1 & +1 & +1 & 3.79 & 2.17 & -1.12 & -2.60 & 4 & -0.65 & $C$ \\
\hline 6 & +1 & -1 & +1 & -1 & +1 & -1 & -1 & 5.64 & 1.95 & 1.22 & -0.06 & 4 & -0.02 & $E$ \\
\hline 7 & -1 & +1 & +1 & -1 & -1 & -1 & -1 & 4.22 & 1.84 & -0.22 & 2.34 & 4 & 0.58 & $F$ \\
\hline 8 & +1 & +1 & +1 & +1 & +1 & +1 & +1 & 6.43 & 2.21 & 0.36 & 0.58 & 4 & 0.15 & $G$ \\
\hline
\end{tabular}

Table 8 Calculation of the effects by means of Yates' algorithm for the response number of graphite counts per square millimeter $\left(\# / \mathbf{m m}^{2}\right)$

\begin{tabular}{|c|c|c|c|c|c|c|c|c|c|c|c|c|c|c|}
\hline \multirow[b]{2}{*}{ Experiment } & \multicolumn{7}{|c|}{ Factors } & \multirow[b]{2}{*}{$\# / \mathbf{m m}^{2}$} & \multirow[b]{2}{*}{$\mathbf{I}$} & \multirow[b]{2}{*}{ II } & \multirow[b]{2}{*}{ III } & \multirow[b]{2}{*}{ Divisor } & \multirow[b]{2}{*}{ Effects } & \\
\hline & $\boldsymbol{A}$ & $\boldsymbol{B}$ & $C$ & $D$ & $E$ & $F$ & $G$ & & & & & & & \\
\hline 1 & -1 & -1 & -1 & +1 & +1 & +1 & -1 & 261 & 666 & 1452 & 2287 & 8 & 286 & Mean \\
\hline 2 & +1 & -1 & -1 & -1 & -1 & -1 & +1 & 406 & 786 & 834 & 983 & 4 & 246 & $A$ \\
\hline 3 & -1 & +1 & -1 & -1 & +1 & -1 & +1 & 222 & 451 & 486 & 53 & 4 & 13 & $B$ \\
\hline 4 & +1 & +1 & -1 & +1 & -1 & +1 & -1 & 564 & 383 & 496 & 148 & 4 & 37 & $D$ \\
\hline 5 & -1 & -1 & +1 & +1 & -1 & +1 & +1 & 89 & 145 & 120 & -618 & 4 & -155 & $C$ \\
\hline 6 & +1 & -1 & +1 & -1 & +1 & -1 & -1 & 362 & 341 & -68 & 10 & 4 & 3 & $E$ \\
\hline 7 & -1 & +1 & +1 & -1 & -1 & -1 & -1 & 80 & 272 & 196 & -188 & 4 & -47 & $F$ \\
\hline 8 & +1 & +1 & +1 & +1 & +1 & +1 & +1 & 304 & 224 & -49 & -245 & 4 & -61 & $G$ \\
\hline
\end{tabular}

Table 9 Calculation of the effects by means of Yates' algorithm, for the response relative percentage of lamellar graphite

\begin{tabular}{|c|c|c|c|c|c|c|c|c|c|c|c|c|c|c|}
\hline \multirow[b]{2}{*}{ Experiment } & \multicolumn{7}{|c|}{ Factors } & \multirow[b]{2}{*}{ Lamellar graphite (\%) } & \multirow[b]{2}{*}{$\mathbf{I}$} & \multirow[b]{2}{*}{ II } & \multirow[b]{2}{*}{ III } & \multirow[b]{2}{*}{ Divisor } & \multirow[b]{2}{*}{ Effects } & \\
\hline & $\boldsymbol{A}$ & $\boldsymbol{B}$ & $C$ & $D$ & $\boldsymbol{E}$ & $\boldsymbol{F}$ & $\boldsymbol{G}$ & & & & & & & \\
\hline 1 & -1 & -1 & -1 & +1 & +1 & +1 & -1 & 21.41 & 45.67 & 92.24 & 164.02 & 8 & 20.50 & Mean \\
\hline 2 & +1 & -1 & -1 & -1 & -1 & -1 & +1 & 24.26 & 46.57 & 71.78 & 19.92 & 4 & 4.98 & $A$ \\
\hline 3 & -1 & +1 & -1 & -1 & +1 & -1 & +1 & 21.75 & 37.37 & 5.92 & -2.06 & 4 & -0.51 & $B$ \\
\hline 4 & +1 & +1 & -1 & +1 & -1 & +1 & -1 & 24.82 & 34.41 & 14.00 & -4.35 & 4 & -1.09 & $D$ \\
\hline 5 & -1 & -1 & +1 & +1 & -1 & +1 & +1 & 14.04 & 2.85 & 0.90 & -20.46 & 4 & -5.12 & $C$ \\
\hline 6 & +1 & -1 & +1 & -1 & +1 & -1 & -1 & 23.32 & 3.07 & -2.96 & 8.07 & 4 & 2.02 & $E$ \\
\hline 7 & -1 & +1 & +1 & -1 & -1 & -1 & -1 & 14.85 & 9.28 & 0.21 & -3.86 & 4 & -0.96 & $F$ \\
\hline 8 & +1 & +1 & +1 & +1 & +1 & +1 & +1 & 19.56 & 4.72 & -4.56 & -4.77 & 4 & -1.19 & $G$ \\
\hline
\end{tabular}


Table 10 Calculation of the effects by means of Yates' algorithm, for the response given by the ratio of Feret diameters

\begin{tabular}{|c|c|c|c|c|c|c|c|c|c|c|c|c|c|c|}
\hline \multirow[b]{2}{*}{ Experiment } & \multicolumn{7}{|c|}{ Factors } & \multirow[b]{2}{*}{$F_{\max } / F_{\min }$} & \multirow[b]{2}{*}{$\mathbf{I}$} & \multirow[b]{2}{*}{ II } & \multirow[b]{2}{*}{ III } & \multirow[b]{2}{*}{ Divisor } & \multirow[b]{2}{*}{ Effects } & \\
\hline & $A$ & $\boldsymbol{B}$ & $C$ & $D$ & $E$ & $F$ & $\boldsymbol{G}$ & & & & & & & \\
\hline 1 & -1 & -1 & -1 & +1 & +1 & +1 & -1 & 2.47 & 6.27 & 12.10 & 21.69 & 8 & 2.71 & Mean \\
\hline 2 & +1 & -1 & -1 & -1 & -1 & -1 & +1 & 3.80 & 5.82 & 9.59 & 2.67 & 4 & 0.67 & $A$ \\
\hline 3 & -1 & +1 & -1 & -1 & +1 & -1 & +1 & 2.68 & 5.17 & 1.79 & -1.20 & 4 & -0.30 & $B$ \\
\hline 4 & +1 & +1 & -1 & +1 & -1 & +1 & -1 & 3.14 & 4.42 & 0.88 & -1.38 & 4 & -0.34 & $D$ \\
\hline 5 & -1 & -1 & +1 & +1 & -1 & +1 & +1 & 2.24 & 1.33 & -0.45 & -2.51 & 4 & -0.63 & $C$ \\
\hline 6 & +1 & -1 & +1 & -1 & +1 & -1 & -1 & 2.93 & 0.46 & -0.74 & -0.91 & 4 & -0.23 & $E$ \\
\hline 7 & -1 & +1 & +1 & -1 & -1 & -1 & -1 & 2.12 & 0.69 & -0.87 & -0.29 & 4 & -0.07 & $F$ \\
\hline 8 & +1 & +1 & +1 & +1 & +1 & +1 & +1 & 2.31 & 0.19 & -0.51 & 0.37 & 4 & 0.09 & $G$ \\
\hline
\end{tabular}

Table 11 Calculation of the effects, by means of the Yates' algorithm, for the response Charpy U-notched specimens absorbed energy tested at $350{ }^{\circ} \mathrm{C}$ in Joules

\begin{tabular}{|c|c|c|c|c|c|c|c|c|c|c|c|c|c|c|}
\hline \multirow[b]{2}{*}{ Experiment } & \multicolumn{7}{|c|}{ Factors } & \multirow[b]{2}{*}{ KU (300 J) (J) } & \multirow[b]{2}{*}{$\mathbf{I}$} & \multirow[b]{2}{*}{ II } & \multirow[b]{2}{*}{ III } & \multirow[b]{2}{*}{ Divisor } & \multirow[b]{2}{*}{ Effects } & \\
\hline & $\boldsymbol{A}$ & $\boldsymbol{B}$ & $C$ & $D$ & $E$ & $F$ & $G$ & & & & & & & \\
\hline 1 & -1 & -1 & -1 & +1 & +1 & +1 & -1 & 7.20 & 14.70 & 29.60 & 60.90 & 8 & 7.61 & Mean \\
\hline 2 & +1 & -1 & -1 & -1 & -1 & -1 & +1 & 7.50 & 14.90 & 31.30 & 1.50 & 4 & 0.38 & $A$ \\
\hline 3 & -1 & +1 & -1 & -1 & +1 & -1 & +1 & 7.20 & 16.20 & 0.80 & -0.90 & 4 & -0.23 & $B$ \\
\hline 4 & +1 & +1 & -1 & +1 & -1 & +1 & -1 & 7.70 & 15.10 & 0.70 & -0.30 & 4 & -0.08 & $D$ \\
\hline 5 & -1 & -1 & +1 & +1 & -1 & +1 & +1 & 7.80 & 0.30 & 0.20 & 1.70 & 4 & 0.42 & $C$ \\
\hline 6 & +1 & -1 & +1 & -1 & +1 & -1 & -1 & 8.40 & 0.50 & -1.10 & -0.10 & 4 & -0.02 & $E$ \\
\hline 7 & -1 & +1 & +1 & -1 & -1 & -1 & -1 & 7.50 & 0.60 & 0.20 & -1.30 & 4 & -0.33 & $F$ \\
\hline 8 & +1 & +1 & +1 & +1 & +1 & +1 & +1 & 7.60 & 0.10 & -0.50 & -0.70 & 4 & -0.18 & $G$ \\
\hline
\end{tabular}

Table 12 Significant factors and levels providing an increase in the selected responses

\begin{tabular}{|c|c|c|c|c|}
\hline \multirow[b]{2}{*}{ Response } & \multirow{2}{*}{\multicolumn{2}{|c|}{ Significant factors }} & \multicolumn{2}{|c|}{ Highest slope level } \\
\hline & & & Level & Corresponding value \\
\hline \multirow[t]{3}{*}{$V_{\mathrm{v}}(\%)$} & $C$ & Liquidus temperature & -1 & $1210-1215^{\circ} \mathrm{C}$ \\
\hline & $F$ & SiCaMn & +1 & $0.5 \mathrm{~kg} / \mathrm{T}$ \\
\hline & $A$ & $\% \mathrm{Si}$ & +1 & $1.1-1.2$ \\
\hline \multirow[t]{2}{*}{$\# / \mathrm{mm}^{2}$} & $C$ & Liquidus temperature & -1 & $1210-1215^{\circ} \mathrm{C}$ \\
\hline & $A$ & $\% \mathrm{Si}$ & +1 & $1.1-1.2$ \\
\hline \multirow[t]{3}{*}{ Lamellar graphite (\%) } & $C$ & Liquidus temperature & -1 & $1210-1215^{\circ} \mathrm{C}$ \\
\hline & $A$ & $\% \mathrm{Si}$ & +1 & $1.1-1.2$ \\
\hline & $B$ & Type A-Ferrosilicon & +1 & $1.6 \mathrm{~kg} / \mathrm{T}$ \\
\hline \multirow[t]{2}{*}{$F_{\max } / F_{\min }$} & $C$ & Liquidus temperature & -1 & $1210-1215^{\circ} \mathrm{C}$ \\
\hline & $A$ & $\% \mathrm{Si}$ & +1 & $1.1-1.2$ \\
\hline \multirow[t]{2}{*}{$\mathrm{KU}(300 \mathrm{~J})(\mathrm{J})$ at $350^{\circ} \mathrm{C}$} & $C$ & Liquidus temperature & +1 & $1230-1235^{\circ} \mathrm{C}$ \\
\hline & $A$ & $\% \mathrm{Si}$ & +1 & $1.1-1.2$ \\
\hline
\end{tabular}

for the standardized effects and probability percent respectively, indicating that the mean of the distribution is zero. The slope of the line represents the magnitude of the experimental error. Thus, nearly horizontal straight lines will indicate higher variability.

The experimental response is subjected to a random variation. This variation follows a normal law, where its standard deviation represents the experimental error. The effects are linear combinations of the responses; hence by application of the limit central theorem, they follow a normal law. If all the effects were nonsignificant, they would follow an $N(0, \sigma)$ distribution, thus appearing aligned when represented on a normal probability plot. However, under the hypothesis of significant and nonsignificant effects represented on the same normal probability plot, the significant effects follow an $N(\mu, \sigma)$ distribution, represented by points which are off the straight line defined by the significant points.

As a result, each effect can be considered as a random variable, its determined value being an estimate of its arithmetic mean. Therefore this value is accompanied by its standard deviation. This allows us to decide as to when a given effect is significant by comparing the ratio given by the mean value over its standard deviation with the critical value of the $95 \%$ confidence limit of the Student- $t$ statistic.

The responses measured from micrographs are summarized in Fig. 2-5. The results in the graphs are the standardized effects represented on a normal probabilistic plot. Figure 2 shows that the significant effects for the volume fraction of graphite are: $A(\% \mathrm{Si}), F(\mathrm{SiCaMn}$, inoculant), and $C$ (liquidus 


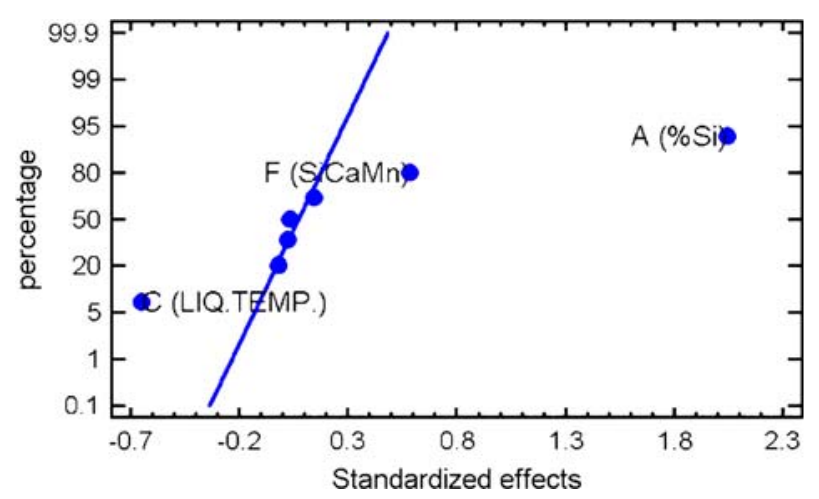

Fig. 2 Normal probability plot for the volume fraction of graphite

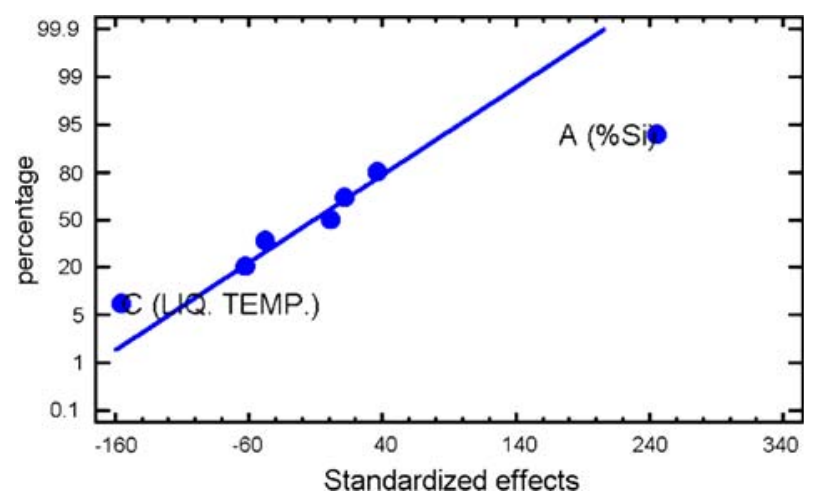

Fig. 3 Normal probability plot for the graphite count number per square millimeter

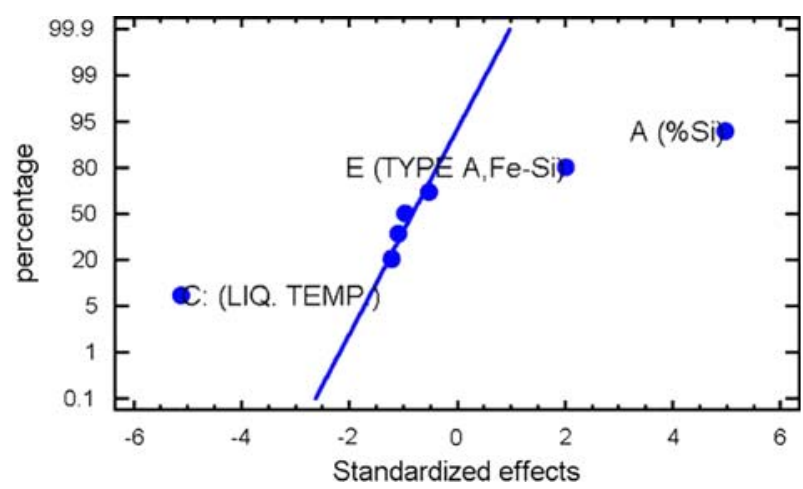

Fig. 4 Normal probability plot for the percentage of laminar graphite

temperature). It should be pointed out that their corresponding levels, i.e. $A(+1), F(+1)$, and $C(-1)$, promote the increase in the graphite volume fraction. Figure 3 shows that two effects are significant for the number of counts of graphite per square millimeter: $A(\% \mathrm{Si})$ and $C$ (liquidus temperature). It is also concluded that their levels $A(+1)$ and $C(-1)$ stimulate an increase of the number of counts per unit area. Figure 4 shows that the significant effects for the percentage of lamellar graphite are: $A(\% \mathrm{Si}), E$ (A-type Ferrosilicon, inoculant), and $C$ (liquidus temperature). It is concluded that the following levels of the effects: $A(+1), E(+1)$, and $C(-1)$, promote the increase in graphite with a lamellar morphology based upon the roundness factor. Figure 5 shows that the only significant effect for the

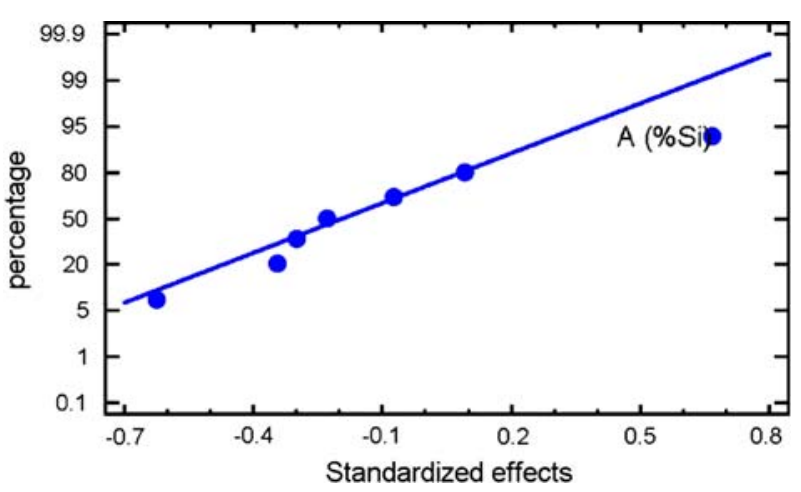

Fig. 5 Normal probability plot for the ratio of maximum between Feret diameters

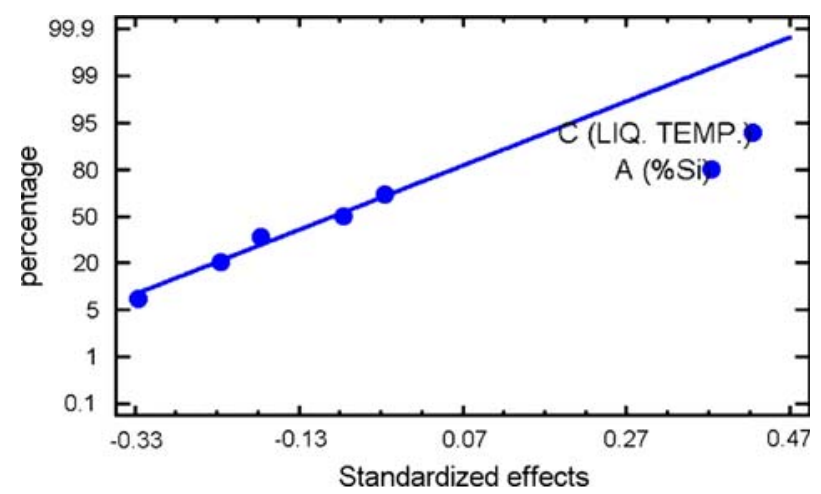

Fig. 6 Normal probability plot for the absorbed energy at $350{ }^{\circ} \mathrm{C}$ after U-notched Charpy testing

graphite Feret diameter quotient is $A(\% \mathrm{Si})$ at its +1 level. This result complements those derived from Fig. 4.

As for the impact behavior of samples in the eight experiments, the summary of the effects is represented in Fig. 6. It can be seen that the significant effects for the hot Charpy test conducted at $350{ }^{\circ} \mathrm{C}$ are: $A(\% \mathrm{Si})$ and $C$ (liquidus temperature), indicating that their levels $A(+1)$ and $C(+1)$ favor an increase in toughness.

Table 12 represents a summary of the results, including the level that defines the steepest ascent gradient permitting an increase in each of the studied variables.

\section{Conclusions}

The statistical method of experimentation conducted on mottled Nihard cast irons confirmed that the effects influencing graphite precipitation coincide with those in gray cast irons. These effects are: the liquidus temperature, the $\% \mathrm{Si}$, inoculation with $\mathrm{SiCaMn}$, and with A-type FeSi. However the analysis also showed the significant effects of the following.

Silicon percentages in the final melt of between 1.1 and 1.2 and a liquidus temperature in the range of $1210-1215{ }^{\circ} \mathrm{C}$ favor an increase in the volume fraction, the number of counts per unit area, and the laminarity of graphite. An increase in the 
amount of SiCaMn added to the pouring ladle as inoculant of the melt at a level of $0.5 \mathrm{~kg} / \mathrm{T}$ also promotes a higher volume fraction of graphite. Furthermore, the inoculation with A-type Ferrosilicon at the usual operating conditions enhances the laminarity of the graphite phase, in combination with the aforementioned factors.

The parameters that promote good toughness behavior at $350{ }^{\circ} \mathrm{C}$ are silicon percentages in the final melt of between 1.1 and 1.2 and a liquidus temperature in the range of 1230$1235^{\circ} \mathrm{C}$.

The final conclusion summarizes the above findings in the following operational recommendation: fixing the liquidus temperature between 1230 and $1235{ }^{\circ} \mathrm{C}$ will favorably influence toughness behavior, while the graphite volume fraction and its morphology may be controlled by increasing the $\% \mathrm{Si}$ in the melt and the amount of added inoculation either of A-type Ferrosilicon and/or SiCaMn to the highest studied level.

\section{Acknowledgments}

The authors wish to thank the University of Oviedo ViceRectorate for Research for providing economic support to carry out the proof-reading of this manuscript.

\section{References}

1. British Rollmakers (China) Ltd., Alloy, Alloy Indefinite Chill (AIC) in Finishing Stand Rolls, http://www.brchina.com/about_brc.htm, Hong Kong (China)
2. J.A. Pero-Sanz, Propiedades generales de las fundiciones grises no aleadas (o de baja aleación) y grafito laminar, Fundiciones Férreas, 1st ed., S.A. Dossat, Ed., 1994 (Madrid), Gráficas ROA S.L., 1994, p 4969 , in Spanish

3. B.T.C. Nycen and T.P. Adams, Cast Iron Indefinite Roll produced by the Addition of $\mathrm{Nb}$. US Patent 6013141, US, 2000

4. J.A. Pero-Sanz, Fundiciones Ni-hard, Fundiciones Férreas, 1st ed., S.A. Dossat, Ed., 1994 (Madrid), Gráficas ROA S.L., 1994, p 124-129, in Spanish

5. American Foundrymen's Society Inc., Nodule Counts, Foundrymen's Guide to Ductile Iron Microstructures, 1st ed., American Foundrymen's Society, Inc., Ed., 1984 (Des Plaines, IL), AFS Press, 1994, p 27-31

6. A. Prat Bartés, X. Tort-Martorell Llabrés, P. Grima Cintas, and L. Pozueta Fernández, Construcción de diseños fraccionales y cálculo de las confusiones introducidas, Métodos Estadísticos, 2nd ed., UPC, Ed., 1997 (Barcelona), S.A. de Litografía, 2000, p 170-172, in Spanish

7. G.E.P. Box, W.G. Hunter, and J.S. Hunter, Concepto de resolución de un diseño, Estadística para Investigadores, 2nd ed., Reverté Ediciones S.A., Ed., 1999 (Méjico), Programas Educativos S.A. de C.V., 2002, p 396-401, in Spanish (translated with permission from John Wiley \& Sons of the original book entitled, Statistics for Experimenters. An introduction to Design, Data Analysis and Model Building)

8. G.F. Vander Voort (1984) Quantitative Microscopy, Metallography Principles and Practice, 1st ed., McGraw-Hill, Inc., Ed., 1984 (New York), Jay's Publishers Services, p 410-502

9. Comité Técnico ECIIS/TC1a, "Ensayo de flexión por choque sobre probetas Charpy. Parte 1: Método de ensayo", EN 10 045-1, European Committee for Standardization-AENOR, Ensayos de Materiales, p 1-14, in Spanish

10. G.E.P. Box, W.G. Hunter, and J.S. Hunter, Apéndice 10A-Algoritmo de Yates, Estadística para Investigadores, 2nd ed., S.A. Reverté Ediciones, Ed., 1999 (Méjico), Programas Educativos S.A. de C.V., 2002, p 355-360, in Spanish (translated with permission from John Wiley \& Sons, Statistics for Experimenters. An introduction to Design, Data Analysis and Model Building) 